\title{
First Successful Full Term Pregnancy Outcome in Latvia Following a Radical Trachelectomy for the Patient with a Combined Pathology of a Cervical Cancer and Severe Subfertility
}

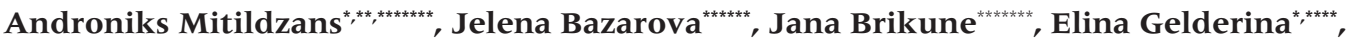

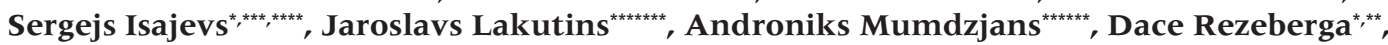 \\ Zenons Romanovskis ${ }^{*}$, Sandra Vitina ${ }^{* * * * *}$ \\ * Riga Eastern Clinical University Hospital \\ ** Riga Stradins University, Department of Obstetrics and Gynecology \\ $* * *$ Riga Eastern Clinical University Hospital, Department of pathology \\ $* * * *$ University of Latvia Faculty of Medicine \\ $* * * * *$ Pauls Stradins Clinical University Hospital \\ ****** Hull and East Yorkshire Women and Children's Hospital, Kingston-upon-Hull, UK \\ $* * * * * *$ AVA-Clinic
}

\begin{abstract}
Summary
Traditionally the treatment for invasive cervical carcinoma which has progressed beyond micro invasion has been radical hysterectomy, unfortunately directly affecting fertility. Long term experience of radical surgery for Stage IB carcinoma has shown that it produces excellent results in terms of survival; however there is always a loss of potential for future fertility. Increasingly large numbers of young women (24-35 years) are being diagnosed with cervical cancer (7). Saving uterus where is safely possible is the main challenge to a surgeon as the loss of fertility for women can be devastating.

Approximately one-third of infertility is attributed to the female partner, one-third attributed to the male partner and one-third is caused by a combination of problems in both partners..

The incidence of a cervical cancer diagnosis in reproductive age women has increased in parallel to the quality in diagnostic in Latvia. However along with a scientifically evident knowledge, new surgical techniques and modern technologies we have recently started implementation of a fertility saving surgeries.
\end{abstract}

Key words: cervical carcinoma, radical trachelectomy, abdominal radical trachelectomy (ART), onco-gynaecology, childbearing, reproductive medicine

\section{AIM OF THE DEMONSTRATION}

A preservation of the reproductive organ and its main function of a nulliparous woman by a radical trachelectomy and successful assisted pregnancy.

\section{CASE REPORT}

A 28 year old nulliparous woman was reviewed by a gynaecologist in February 2013 with a failed conception trial after 2 years of unprotected vaginal sexual intercourse and a previous history of a right salpingectomy in 2010 due to a diagnosed right tubal ectopic pregnancy as well as; beforehand, 5 consecutives early miscarriages. Her partner was diagnosed with astenoteratozoospermy. Due to a suspicious looking cervix, cytology and histology testing was performed confirming G2 squamous cell carcinoma. US abdomen and pelvis along with MRI did not confirm invasion in parametrial and pelvic lymphnodes. Clinical Diagnosis on $8 / 4 / 2013$ was a Cervical cancer stage IB 1, $\mathrm{CT}_{1 \mathrm{bl}} \mathrm{N}_{0} \mathrm{M}_{0} \mathrm{G}_{2}$. Therefore Radical trachelectomy with bilateral pelvic lymphadenectomy was indicated. Intraoperative findings were: excessive pelvic adhesions likely caused by the pelvic inflammatory disease in past. Adhesiolysis performed, followed by the bilateral parailiacal lymphaedenectomy along with an excision of common, external and internal as well as obturator lymph nodes (Fig. 1.).

The specimen (frozen section) was urgently investigated and once metastases excluded, the surgery was continued by a radical trachelectomy in the steps. Firstly we performed the bladder dissection downwards from cervix and upper vagina. Subsequently uterine vessels were ligated and divided in their origin. Each ureter was mobilized off its peritoneal attachment and dissected down to the bladder. The parametrial tissues and uterosacral ligaments were divided. After division of the uterosacral ligaments, the cardinal ligaments were clamped. Uterine perfusion was secured by the ovarian vessels only. The uterine body was disected from the cervix. A resection line (frozen section) was confirmed of being clear, therefore was proceeded to the cervical excision along with the para-cervical tissues and an upper third of vagina. An internal cervical os was secured by the circular Ethybond suture. The uterine 
body was rejoined to the cervix by using Sturmdorf sutures (Fig.2.). Postoperatively a good recovery was demonstrated therefore on day 4 patient was discharged home in a satisfactory condition.

The histology report confirmed - G2 squamous cell carcinoma with a tendency of keratinisation, invasive growth up to $3 \mathrm{~mm}$, no metastases in lymph nodes and a diagnosis confirmed: Cervical cancer stage IB I pTlblN0M0G2. On a regular follow up review in 4 months cofirmed: clinically, imaging and cervical cytology without an evidence of a progression of the disease.

In a year time since the surgery performed an assisted conception was employed. Intracytoplasmic sperm injection technique with a partners sperm used and one embrio transfer completed, elective additional cerclage vaginally performed at 15 weeks of pregnancy and at the gestation of 38 weeks a healthy baby was born via elective ceaserean section.

\section{DISCUSSION}

Typically, radical hysterectomy with bilateral pelvic lymphadenectomy is practiced not only for stages IA2/IB 1 but also for high-risk IA l like lymphovascular invasion. Fertility preservation techniques are recommended only in selected IBI patients, with tumours less than $2 \mathrm{~cm}$ and the common practice is bilateral pelvic lymphadenectomy and radical trahelectomy with or without sentinel lymph node biopsy $(2,3)$. In case with a cervical malignancy the options for fertility preservation with early-stage cervical cancer is available from a team of clinicians who are experts of reproductive medicine in cooperation with an experienced gynecologic oncologist. With this being the first successful case, of this nature, in Latvia, it sets a precedent for current and future doctors in training, which in conjunction with relevant, scientific and evidence based medicine and literature, which will assist greatly in the development and the practice of this particular procedure within Latvia.

\section{CONCLUSION}

Evidence based and properly selected surgical methods in combination with contemporary scientific technologies allow us to save fertility even following radical major surgeries.

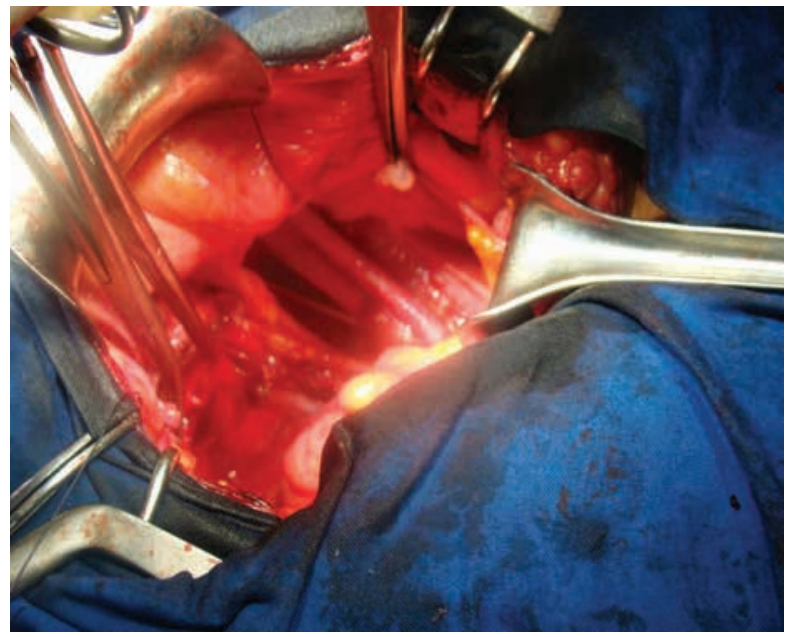

Fig. 1. Bilateral ilaiac lympho-dissecton

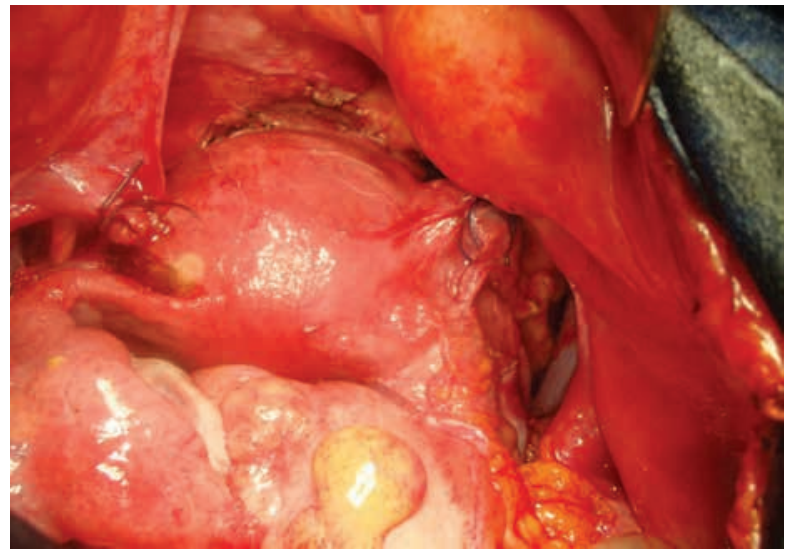

Fig. 2. Final stage - after uterus rejoined to a vagina

Conflict of interest: None 


\section{REFERENCES}

1. CRC. Cervical screening Factsheet 13.1. Cancer Research Campaign, 1994

2. Diaz, J.P., Sonoda, Y., et al.: Oncologic outcome of fertilitysparing radical trachelectomy versus radical hysterectomy for stage IB I cervical carcinoma. In: Gynecol Oncol 2008; vol. 111, p. 255-260

3. French DB, Sabanegh ES, Goldfarb J, Desai N (March 2010). "Does severe teratozoospermia affect blastocyst formation, live birth rate, and other clinical outcome parameters in ICSI cycles?". Fertil Steril 93 (4): 1097-1103. 10.1016/j. fertnstert.2008.10.051. PMID 19200957

4. Hiroshi Nishio; Takuma Fujii; Juri Sugiyama; Naoaki Kuji; Mamoru Tanaka; Toshio Hamatani; Kei Miyakoshi; Kazuhiro Minegishi; Hiroshi Tsuda; Takashi Iwata; Kyoko Tanaka; Takeshi Fukuchi; Yuji Takehara; Yasunori Yoshimura; Daisuke Aoki. Reproductive and Obstetric Outcomes After Radical Abdominal Trachelectomy for Early-Stage Cervical Cancer in a Series of 31 Pregnancies. HumReprod. 2013;28(7):1793-1798
5. Nishio $\mathrm{H}^{1}$, Fujii $\mathrm{T}$, Sugiyama J, Kuji $\mathrm{N}$, Tanaka M, Hamatani T, Miyakoshi K, Minegishi K, Tsuda H, Iwata T, Tanaka K, Fukuchi T, Takehara Y, Yoshimura Y, Aoki D. Reproductive and obstetric outcomes after radical abdominal trachelectomy for early-stage cervical cancer in a series of 31 pregnancies

6. Raju, S.K., Papadopoulos, A.J., et al.: Fertilitysparing surgery for early cervical cancer-approach to less radical surgery. In: Int J Gynecol Cancer 2012, vol. 22, p. 311-317

7. World Cancer Report 2014. World Health Organization. 2014. pp. Chapter 5.12. ISBN 9283204298

8. http://www.ivfriga.lv/maksliga-apauglosana/icsimanipulacija.html

\section{Address:}

Androniks Mitildzans,

Riga Eastern Clinical University Hospital, Hipokrata Street 2, LV-1038, Riga, Latvia, e-mail: andronmit@inbox.lv 